\title{
Parental history of depression or anxiety and the cortisol awakening response
}

Sophie A. Vreeburg, Catharina A. Hartman, Witte J. G. Hoogendijk, Richard van Dyck, Frans G. Zitman, Johan Ormel and Brenda W. J. H. Penninx

\section{Background}

It is unclear whether altered hypothalamic-pituitary-adrenal (HPA) axis regulation, which frequently accompanies depression and anxiety disorders, represents a trait rather than a state factor.

\begin{abstract}
Aims
To examine whether HPA axis dysregulation represents a biological vulnerability for these disorders, we compared cortisol levels in unaffected people with and without a parental history of depressive or anxiety disorders. We additionally examined whether possible HPA axis dysregulations resemble those observed in participants with depression or anxiety disorders.
\end{abstract}

\section{Method}

Data were from the Netherlands Study of Depression and Anxiety. Within the participants without a lifetime diagnoses of depression or anxiety disorders, three groups were distinguished: 180 people without parental history, 114 with self-reported parental history and 74 with CIDI-diagnosed parental history. These groups were additionally compared with people with major depressive disorder or panic disorder with agoraphobia $(n=1262)$. Salivary cortisol samples were obtained upon awakening, and 30, 45 and 60 min later.

\section{Results}

As compared with unaffected participants without parental history, unaffected individuals with diagnosed parental history of depression or anxiety showed a significantly higher cortisol awakening curve (effect size $(d)=0.50$ ), which was similar to that observed in the participants with depression or anxiety disorders. Unaffected people with self-reported parental history did not differ in awakening cortisol levels from unaffected people without parental history.

\section{Conclusions}

Unaffected individuals with parental history of depression or anxiety showed a higher cortisol awakening curve, similar to that of the participants with depression or anxiety disorders. This suggests that a higher cortisol awakening curve reflects a trait marker, indicating an underlying biological vulnerability for the development of depressive and anxiety disorders.

\section{Declaration of interest}

None.
Dysregulation of the hypothalamic-pituitary-adrenal (HPA) axis is believed to play a key role in the pathophysiology of depression. ${ }^{1}$ Moreover, depression and its course may be partly genetically determined. ${ }^{2-5}$ We previously found a higher cortisol awakening response in people with a current or a remitted major depressive disorder. ${ }^{6}$ Together with other reports, this may indicate that HPA axis dysregulation represents a trait rather than a state marker. ${ }^{7}$ A similarly elevated cortisol awakening response was observed for current panic disorder with agoraphobia. ${ }^{8}$ To further investigate whether this dysregulation of the cortisol morning curve represents a trait marker and whether it reflects a biological vulnerability for, rather than a consequence (i.e. a biological 'scar') of, depression or anxiety disorders it is essential to know whether it is present before the onset of the disorder. Family inheritance is one of the most reliable risk factors of depression. ${ }^{3}$ Recent studies have examined parental history of depression and cortisol morning levels in people without depression, and showed higher ${ }^{9}$ or similar levels of morning cortisol ${ }^{10,11}$ compared with people without parental history. However, these studies had a limited sample size, used limited morning cortisol samples, did not include anxiety disorders or adjust for important confounders, such as smoking or sleep duration. In addition, these studies did not compare cortisol levels of unaffected people with those of people with depression or anxiety disorders. Therefore, we examined differences in 1-h awakening cortisol between unaffected people with and without parental history of depression and/or anxiety. We included an additional comparison group of participants with depression or anxiety disorders and accounted for important covariates, subthreshold symptoms, adverse childhood experiences, life events and neuroticism.

\section{Method}

Data are from the baseline assessment (September 2004 to February 2007) of the Netherlands Study of Depression and Anxiety (NESDA). ${ }^{12}$ Respondents (aged 18-65) were recruited from the community, general practice and specialised mental healthcare services, and included people with and without psychopathology. General exclusion criteria were: a primary diagnosis of psychotic disorder, obsessive-compulsive disorder, bipolar disorder or severe addiction disorder and not being fluent in Dutch. The research protocol was approved by the Ethical Committee of participating universities and all respondents provided written informed consent.

Within the participants with no lifetime history of panic disorder, generalised anxiety disorder, agoraphobia, social phobia, major depressive disorder or dysthymia as assessed by the DSM-IV Composite International Diagnostic Interview (CIDI version 2.1) ${ }^{13}$ and no subthreshold symptoms (Beck Anxiety Inventory $(\mathrm{BAI}) \leqslant 20,{ }^{14}$ Inventory of Depressive Symptoms $($ IDS $) \leqslant 14)^{15}$ or use of antidepressants or benzodiazepines, three groups were compared.

\section{Participants without parental history}

These participants reported no parental history of depression or anxiety disorder, as assessed by the family history inventory $(n=238)$ on which the respondent reported on the presence of an anxiety or depressive disorder in all individual first-degree relatives. 


\section{Participants with self-reported parental history}

These participants reported at least one biological parent with depression and/or anxiety $(n=173)$.

\section{Participants with diagnosed parental history}

These participants $(n=122)$ had previously participated in the Adolescents at Risk of Anxiety and Depression (ARIADNE) study ${ }^{16}$ into the development of depression and anxiety disorders among offspring (aged 13-25) of people with psychiatric disorders, approximately 4 years before participating in NESDA. Parents were treated for depression or panic disorder in specialised mental healthcare. Both offspring and parent were interviewed with the CIDI. ${ }^{17}$

\section{Comparison group}

A comparison group of participants consisted of 2010 people who were diagnosed with a remitted or current major depressive disorder and/or current panic disorder with agoraphobia as assessed by the CIDI, for whom we observed the highest cortisol levels as compared to people without psychopathology. ${ }^{6,8}$

\section{Exclusions and final sample}

We subsequently excluded 22 pregnant or breastfeeding women and 140 participants on corticosteroids, leaving 2381 respondents. Of these, $1630(68.5 \%)$ returned sufficient saliva samples: 180 (81.8\%) without parental history; $114(70.4 \%)$ with self-reported parental history; 74 (61.7\%) with diagnosed parental history and $1262(67.2 \%)$ with a psychiatric diagnosis, $P<0.001)$.

\section{Salivary cortisol}

A minimally intrusive way to measure basal cortisol level is through saliva sampling, reflecting the active unbound form of cortisol. ${ }^{18}$ As described in more detail elsewhere, ${ }^{19}$ participants were instructed to collect saliva samples at home on a regular (working) day shortly after the interview. Instructions concerning saliva sampling prohibited smoking, eating, drinking tea or coffee or brushing teeth within 15 min before sampling. Furthermore, no dental work $24 \mathrm{~h}$ prior to sampling was allowed. Saliva samples were obtained using Salivettes (Sarstedt, Germany) at four time points; upon awakening $\left(T_{1}\right)$ and $30\left(T_{2}\right), 45\left(T_{3}\right)$ and $60\left(T_{4}\right)$ min later. After return by mail, samples were stored at $-80^{\circ} \mathrm{C}$. Cortisol analysis was performed by competitive electrochemiluminescence immunoassay (E170 Roche, Switzerland). The functional detection limit was $2.0 \mathrm{nmol} / \mathrm{l}$ and the intra- and interassay variability coefficients in the measuring range were less than $10 \%$. Data cleaning excluded values $>2$ standard deviations above the mean.

In addition to conducting linear mixed models analyses (see statistical analyses section) using all four morning saliva samples, we calculated the area under the curve with respect to the increase $\left(\mathrm{AUC}_{\mathrm{i}}\right)$ and with respect to the ground $\left(\mathrm{AUC}_{\mathrm{g}}\right)$ using Pruessner's formulas. $^{20}$ The $\mathrm{AUC}_{\mathrm{g}}$ is an estimate of the total cortisol secretion over the first hour after awakening, whereas the $\mathrm{AUC}_{\mathrm{i}}$ is a measure of the dynamic of the cortisol awakening response, more related to the sensitivity of the system, emphasising changes over time after awakening. ${ }^{21-23}$ If samples were collected outside of a margin of $5 \mathrm{~min}$ around the time protocol, values were assigned missing. Morning cortisol analyses included all participants with at least two valid morning cortisol values $(n=1630)$, since linear mixed models analyses can adequately interpolate for missing data. ${ }^{24}$ For 1441 participants all four morning samples were available and could therefore be included in the AUC analyses (158 without parental history, 101 with self-reported parental history, 68 with diagnosed parental history and 1114 with a psychiatric diagnosis).

\section{Covariates}

Previously, we described effects of gender, age, time of awakening, working status, season, sleep duration, physical activity and smoking on salivary cortisol levels, ${ }^{19}$ which were considered as covariates. Respondents reported time of awakening and working status on the sampling day. Season was categorised into less (October through to February) and more daylight (March through to September) months. Average sleep duration during the past 4 weeks was dichotomised as $\leqslant 6$ or $>6 \mathrm{~h} / \mathrm{night},{ }^{25}$ and smoking status as current versus non-smoker. Physical activity was assessed using the International Physical Activity Questionnaire and expressed in 1000 MET-min (metabolic energy turnover per min) a week. ${ }^{26}$ Menstrual cycle phase, menopausal status or use of oral contraceptives were not associated with salivary cortisol and were therefore not included as covariates. ${ }^{19}$

\section{Explanatory factors}

To examine whether found effects were influenced by neuroticism, childhood trauma and life events we adjusted all analyses for these factors. Neuroticism was measured with the 12-item subscale of the NEO Five-Factor Inventory (NEO-FFI) Questionnaire ${ }^{27}$ ranging from 0 (low neuroticism) to 48 (high neuroticism). In order to examine the role of earlier childhood trauma, we constructed a cumulative childhood trauma index using the NEMESIS childhood trauma interview, ${ }^{6}$ which summarises the frequency of four reported traumas before the age of $16-$ emotional neglect, psychological abuse, physical abuse and sexual abuse - resulting in an index score between 0 and 8 . Finally, negative life events in the past year were assessed by the Brugha questionnaire $^{28}$ and included 12 specific events and one 'other' category asking about another serious (not specified) negative life event. Since symptom severity scores were not associated with salivary cortisol levels in our previous studies, these were not included as covariates. ${ }^{6,8}$

\section{Statistical analyses}

Baseline characteristics were compared using $\chi^{2}$ and ANOVA statistics. Area under the curves showed normal distributions, 1-h awakening cortisol levels were slightly skewed and therefore log-transformed for linear mixed models analyses. Backtransformed values were used in the figure. To analyse differences in 1-h awakening cortisol across groups, ANCOVA analyses with $\mathrm{AUC}_{\mathrm{i}}$ and $\mathrm{AUC}_{\mathrm{g}}$ were conducted. First, we compared the three unaffected parental history groups. Additionally, parental history groups were compared with the group of participants with a psychiatric diagnosis. Random coefficient analysis of the four morning cortisol levels was performed using linear mixed models, which keeps original values on all four data points, can accommodate for incomplete cases, and takes correlation between repeated measurements into account. ${ }^{24}$ Parental history groups, time point $\left(T_{1}, T_{2}, T_{3}, T_{4}\right)$ and all covariates were entered as fixed factors, participants were treated as a random effect and a random intercept was estimated. To examine whether the course of cortisol level after awakening was different across groups, we added a group $\times$ time interaction term. For significant findings, effect sizes were calculated with Cohen's $d$. All analyses were conducted using SPSS version 15.0 for Windows.

\section{Results}

Sample characteristics are presented in Table 1. Participants with diagnosed parental history were younger, had later awakening times, less often slept $\leqslant 6 \mathrm{~h} / \mathrm{night}$, had a lower trauma index score 


\begin{tabular}{|c|c|c|c|c|}
\hline & \multicolumn{3}{|c|}{ Participants without lifetime depression/anxiety } & \multirow{2}{*}{$\begin{array}{c}\text { Participants with major } \\
\text { depressive disorder and/or } \\
\text { panic disorder with agoraphobia } \\
(n=1262)\end{array}$} \\
\hline & $\begin{array}{l}\text { No parental } \\
\text { history } \\
(n=180)\end{array}$ & $\begin{array}{l}\text { Self-reported } \\
\text { parental history } \\
\quad(n=114)\end{array}$ & $\begin{array}{l}\text { Diagnosed } \\
\text { parental history } \\
\quad(n=74)\end{array}$ & \\
\hline Female, \% & 57.8 & 57.0 & 58.1 & $68.1^{* *}$ \\
\hline Age, years: mean (s.d.) & $47.9(11.8)$ & $47.8(11.9)$ & $21.6(2.7)^{\star \star}$ & $43.1(12.3)^{* *}$ \\
\hline Time of awakening, mean (s.d.) & 07.00 (1 h 11) & 07.22 (1 h 02) & $07.35(1 \mathrm{~h} \mathrm{11)*}$ & $07.30(1 \mathrm{~h} 13)^{* *}$ \\
\hline Working on day of sampling, \% & 65.9 & 65.8 & 64.4 & $55.9 * \star$ \\
\hline Sampling in month with more daylight, ${ }^{a} \%$ & 56.0 & 48.2 & 50.0 & 54.7 \\
\hline$\leqslant 6 \mathrm{~h}$ of sleep, \% & 18.1 & 15.8 & $4.1 * *$ & $31.3^{* *}$ \\
\hline Smoker, \% & 21.1 & 22.8 & 29.7 & $36.9 * *$ \\
\hline Physical activity, 1000 MET-min/week: mean (s.d.) & $4.0(3.2)$ & $3.8(2.9)$ & $4.1(3.4)$ & $3.7(3.1)$ \\
\hline Life event in past year, \% & 30.0 & 29.8 & $47.3^{* *}$ & $39.1^{* *}$ \\
\hline Trauma index, mean (s.d.) & $0.4(1.1)$ & $0.9(1.7)^{\star \star}$ & $0.1(0.3)^{* *}$ & $1.9(2.2)^{\star \star}$ \\
\hline Neuroticism, mean (s.d.) & $23.8(5.7)$ & $25.0(5.7)^{\star}$ & $28.1(6.7)^{\star *}$ & $39.0(7.9)^{\star *}$ \\
\hline \multicolumn{5}{|l|}{ Type of parental disorder } \\
\hline Anxiety only, \% & NA & 28.1 & 5.9 & NA \\
\hline Depression only, \% & NA & 40.4 & 52.9 & NA \\
\hline Comorbidity, \% & NA & 31.6 & 41.2 & NA \\
\hline $\begin{array}{l}\text { MET, metabolic energy turnover, NA, not applicable. } \\
{ }^{*} P<0.10,{ }^{* \star} P<0.05 \text { compared with unaffected participan } \\
\text { a. March through to September. }\end{array}$ & no parental hi & & & \\
\hline
\end{tabular}

and higher neuroticism scores than other unaffected participants (Table 1). Participants with self-reported parental history reported more childhood trauma and had higher neuroticism scores than unaffected participants without parental history. Compared with parents in the diagnosed parental history group, parents in the self-reported parental history group more often had only anxiety disorders. Diagnosed parents mostly had depression with or without comorbid anxiety disorder.

In total $68.5 \%$ of the respondents showed an increase in cortisol levels within $1 \mathrm{~h}$ of waking up $(65.0 \%$ in the group without parental history, $68.4 \%$ in the self-reported parental history group, $77.0 \%$ in the diagnosed parental history group, $P=0.17)$. Parental history groups showed significant differences in $\mathrm{AUC}_{\mathrm{g}}$ (d.f. $=2 / 316, F=3.47, P=0.03$ ), but not in $\mathrm{AUC}_{\mathrm{i}}$ (d.f. $=2 /$ $316, F=1.73, P=0.18$ ). The group with diagnosed parental history showed higher overall adjusted cortisol levels than participants without parental history, reflected by a larger $\mathrm{AUC}_{\mathrm{g}}(P=0.01$, effect size (Cohen's $d)=0.50$, Table 2) and confirmed by a borderline significant direct effect in linear mixed models analyses $(F=3.39, P=0.07$, data not shown). There was a trend towards a larger $\mathrm{AUC}_{\mathrm{i}}(P=0.08, d=0.35$, Table 2$)$ for the diagnosed parental history group, but the interaction with time was not significant $(F=1.09, P=0.35)$. The group with self-reported parental history did not show significant differences in morning cortisol compared with the group without parental history (Table 2, linear mixed models analyses: direct effect: $F=0.05, P=0.82$; interaction with time: $F=0.85, P=0.47)$.

\section{Additional analyses}

When comparing unaffected people with diagnosed parental history with participants with a psychiatric diagnosis, no difference was observed (mean $\mathrm{AUC}_{\mathrm{g}} 20.0$ (s.e.=0.9) v. 19.5 (s.e.=0.2) nmol/l/h, $P=0.62$, mean $\mathrm{AUC}_{\mathrm{i}} 2.6$ (s.e. $\left.=0.8\right)$ v. $2.6($ s.e. $=0.2) \mathrm{nmol} / \mathrm{l} / \mathrm{h}$, $P=0.46$, respectively, after full adjustment). However, this group of participants with a psychiatric diagnosis did differ from the group without parental history (mean $\mathrm{AUC}_{\mathrm{g}} 17.7$ (s.e.=0.6) $\mathrm{nmol} / \mathrm{l} / \mathrm{h}, \quad P=0.002$, mean $\mathrm{AUC}_{\mathrm{i}} 1.4 \quad$ (s.e.=0.5) nmol/l/h, $P=0.03)$ and participants with self-reported parental history (mean $\mathrm{AUC}_{\mathrm{g}} 17.8$ (s.e. $=0.7$ ) nmol/l//h, $P=0.02$, mean $\mathrm{AUC}_{\mathrm{i}} 2.1$ $($ s.e. $=0.6) \mathrm{nmol} / \mathrm{l} / \mathrm{h}, P=0.46)$. These results are graphically represented in Fig. 1.

Additional adjustment for childhood trauma, neuroticism and life events in the past year did not essentially change results. In order to conduct analyses in which age groups are more equal, we repeated the analyses excluding all participants older than 30 years. Mean $\mathrm{AUC}_{\mathrm{g}}$ was higher for diagnosed parental history (18.6 (s.e. $=0.8) \mathrm{nmol} / \mathrm{l} / \mathrm{h}, P=0.03, d=0.65, n=68)$ and also for

Table 2 Results of age-adjusted and fully adjusted ANCOVA analyses associating parental history with the cortisol awakening curve ${ }^{\text {a }}$

\begin{tabular}{|c|c|c|c|c|c|}
\hline & $\begin{array}{l}\text { No parental history } \\
\qquad(n=183) \\
\text { Mean (s.e.) }\end{array}$ & $\begin{array}{l}\text { Self-reported parental } \\
\text { history }(n=120) \\
\text { Mean (s.e.) }\end{array}$ & $\begin{array}{c}\text { Self-reported } v \text {. no } \\
\text { parental history } \\
P\end{array}$ & $\begin{array}{l}\text { Diagnosed parental } \\
\text { history }(n=73) \\
\text { Mean (s.e.) }\end{array}$ & $\begin{array}{c}\text { Diagnosed } v \text {. no } \\
\text { parental history } \\
P\end{array}$ \\
\hline$A \cup C_{g}, n m o l / l / h^{b}$ & $17.5(0.5)$ & $17.6(0.7)$ & 0.91 & $19.9(1.0)$ & 0.07 \\
\hline $\mathrm{AUC}_{\mathrm{g}}, \mathrm{nmol} / \mathrm{l} / \mathrm{h}^{\mathrm{C}}$ & $17.4(0.5)$ & $17.5(0.6)$ & 0.90 & $20.6(1.0)$ & 0.01 \\
\hline $\mathrm{AUC}_{\mathrm{i}}, \mathrm{nmol} / \mathrm{l} / \mathrm{h}^{\mathrm{b}}$ & $1.0(0.5)$ & $1.7(0.6)$ & 0.38 & $3.1(1.0)$ & 0.09 \\
\hline$A \cup C_{i}, n m o l / l / h^{c}$ & $1.0(0.5)$ & $1.8(0.6)$ & 0.30 & $3.1(1.0)$ & 0.08 \\
\hline \multicolumn{6}{|c|}{$\begin{array}{l}\left.\text { a. Area under the morning curve with respect to the ground }\left(A \cup C_{g}\right)=\left(\left(\left(T_{1}+T_{2}\right) / 2\right) \times 0.5\right)+\left(\left(\left(T_{2}+T_{3}\right) / 2\right) \times 0.25\right)+(((T 3+T 4) / 2) \times 0.25)\right) \text {. Area under the morning curve with respect to } \\
\text { the increase }\left(A \cup C_{i}\right)=A \cup C_{g}-\left(T_{1}(0.5+0.25+0.25)\right){ }^{20} \\
\text { b. Adjusted for age. } \\
\text { c. Additionally adjusted for gender, working status, time of awakening, season, sleep, physical activity and smoking. }\end{array}$} \\
\hline
\end{tabular}



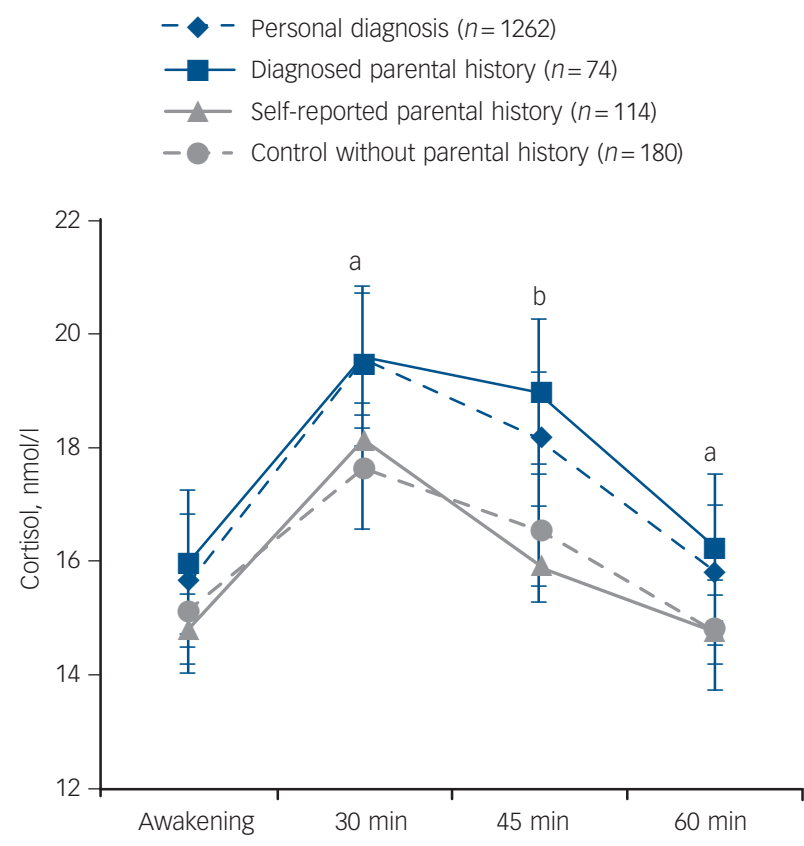

Fig. 1 Mean salivary cortisol levels for unaffected participants without parental history, with self-reported parental history and with diagnosed parental history and for participants with depression or panic disorder.

Adjusted for gender, age, working status, time of awakening, sleep duration, season, physical activity and smoking. Results of linear mixed models analyses (compared with controls without parental history): self-reported parental history: $P=0.92$, with controls without parental history): self-reported parental history: $P=0.92$,
interaction with time: $P=0.48$. Diagnosed parental history: $P=0.07$ and interaction with time: $P=0.62$. Personal diagnosis: $P=0.01$ and interaction with time: $P=0.25$ Error bars illustrate standard errors. (a) $P<0.05$ for group with personal diagnosis compared with controls; (b) $P<0.05$ for personal diagnosis and diagnosed parental history compared with controls.

self-reported parental history $(17.7$ (s.e. $=1.7) \mathrm{nmol} / \mathrm{l} / \mathrm{h}, P=0.13$, $d=0.50, n=13$ ) compared with participants without parental history $(14.5($ s.e. $=1.5) \mathrm{nmol} / \mathrm{l} / \mathrm{h}, n=20)$.

Since the self-reported parental history group had relatively more parents with anxiety compared with depression or comorbidity, we reanalysed differences only including participants with self-reported parental depression or comorbid disorders. Results showed a higher $\mathrm{AUC}_{\mathrm{g}}$ in the diagnosed parental history group (mean $\mathrm{AUC}_{\mathrm{g}}=20.5$ (s.e. $=1.0$ ), $P=0.01$ ) and a similar $\mathrm{AUC}_{\mathrm{g}}$ in the self-reported parental history group (mean $\mathrm{AUC}_{\mathrm{g}}=17.3$ (s.e. $\left.\left.=0.8\right), \quad P=0.96\right)$ as compared with controls $\left(\right.$ mean $\mathrm{AUC}_{\mathrm{g}}=17.3($ s.e. $\left.=0.5) \mathrm{nmol} / \mathrm{l} / \mathrm{h}\right)$.

\section{Discussion}

\section{Main findings}

This study shows that cortisol awakening levels in unaffected participants with diagnosed parental history of depression or anxiety were significantly higher than in unaffected participants without parental history, and similar to those in participants with major depressive disorder or panic disorder with agoraphobia. ${ }^{6,8}$ In fact, the effect size for unaffected participants with diagnosed parental history was medium $(d=0.50)$ and higher than the effect sizes $(d=0.15-0.32)$ previously described for major depressive disorder and panic disorder with agoraphobia. ${ }^{6,8}$ Our results suggest that a higher cortisol awakening curve represents a trait factor and reflects an underlying biological vulnerability marker.

The higher cortisol levels were only found in offspring of patients with a CIDI diagnosis treated in specialised mental healthcare and not in offspring with affected parents based on self-report. Although often used to assess parental history, our findings may indicate that self-report of parental psychopathology is of insufficient reliability. Alternatively, the parents reported on by their offspring may represent the milder cases and be associated with lower familial loading, especially since it was not asked whether parents were treated, in contrast to the diagnosed parents of the ARIADNE sample for whom referral status was required for enrolment in the study. Higher familial loading in the diagnosed parental history group might also be reflected by the higher neuroticism scores in this group relative to the self-reported parental history group. In addition, when excluding participants older than 30 years, effect sizes were higher in both parental history groups relative to the group without parental history, also possibly reflecting the importance of familial loading. Presumably, and consistent with the idea that cortisol elevation represents a liability for later onset of anxiety and depression, part of the younger parental history group may not have developed depression or anxiety yet. However, the older group, being still unaffected, may never develop depression or anxiety disorder. The larger proportion of anxiety disorder without comorbid depression in the self-reported parental history group did not explain the results, since additional analysis excluding anxiety disorder without comorbid depression generated similar results.

Our results are in line with one study reporting higher morning cortisol, ${ }^{9}$ but in contrast with studies reporting no association with morning cortisol in unaffected people with parental history. ${ }^{10,11}$ However, the latter two studies measured the morning curve with only one and two saliva samples, respectively. Participants with diagnosed parental history showed overall higher cortisol levels $\left(\mathrm{AUC}_{\mathrm{g}}\right.$ ) and a trend towards a higher increase $\left(A U C_{i}\right)$, indicating that especially the total cortisol secretion within the first hour after awakening is elevated. This emphasises the importance of collecting multiple morning samples. The increased $\mathrm{AUC}_{\mathrm{g}}$ is possibly reflective of basal hyperactivity of the HPA axis, since it is related to cortisol levels during the rest of the day, whereas the $\mathrm{AUC}_{\mathrm{i}}$ is less dependent on the diurnal cortisol rhythm and is regarded an indicator of reactivity of the HPA axis. ${ }^{21-23}$ It has been hypothesised that the $\mathrm{AUC}_{\mathrm{g}}$ is particularly suited to measure trait effects, whereas the $\mathrm{AUC}_{\mathrm{i}}$ is better suited for state effects. ${ }^{29}$

An important finding was that cortisol levels were comparable with those found in participants with a psychiatric diagnosis. Previous studies did not compare morning cortisol levels of individuals with familial history with people with depression/anxiety. However, reports on cortisol release on the dexamethasone/corticotropin-releasing hormone test showed cortisol levels in between controls and patients. ${ }^{30}$

\section{Genetic factors}

Genetic factors could account for our findings. ${ }^{3,31}$ The cortisol awakening response has a heritability of $32-48 \%{ }^{31,32}$ and depression has a heritability of $37 \% .{ }^{3}$ It could be that the same genes underlie both depression and morning cortisol regulation, for example the serotonin transporter gene, ${ }^{33}$ mineralocorticoid or glucocorticoid receptor genes. ${ }^{2}$ Epigenetic factors such as histone modification or methylation of deoxyribonucleic acid (DNA) as a result of early life stress could also play a role. ${ }^{34}$

Also, early childhood trauma and adversity could be more prevalent in people growing up in families with psychiatric problems, which may exert direct effects on inflammatory and glucocorticoid signalling. ${ }^{35,36}$ However, adjustment for childhood trauma, including emotional abuse, did not change our results, since these variables were not associated with saliva cortisol levels. 
Also subthreshold symptoms, as measured using the IDS or BAI score, were not associated with salivary cortisol levels. ${ }^{6}$ Therefore, it is unlikely that subthreshold symptoms or past traumatic events can completely account for the relationship found in our study. Possibly, a differential home environment due to parental depression could have played a role, for example less structure provided by parents ${ }^{37}$ and chronic family stress. ${ }^{38}$ Exposure to parental depression could also have resulted in more stress among the children, even when the depression is in remission, because of possible personality deviances and role function problems of the parents. $^{39,40}$

\section{Strengths and limitations}

Our study had several strengths, including offspring from parents with confirmed diagnoses, the use of four morning cortisol samples and an additional comparison group of participants with a psychiatric diagnosis. Moreover, we studied an adult sample, whereas most studies included children, showing that HPA axis dysregulations persist into adulthood. Some limitations have to be acknowledged. First, non-adherence to the sampling instructions could have resulted in a blunted cortisol response after awakening. ${ }^{41}$ However, even when awakening is closely monitored at least $15 \%$ of all participants still do not respond with a cortisol rise. ${ }^{42}$ Moreover, we have no reason to believe that possible non-adherence is unevenly distributed among our groups. Second, since the majority of parents with a diagnosis had a depressive disorder, our results are mostly restricted to depression with or without comorbid anxiety. Future studies are warranted to specifically examine HPA axis activity and parental history of anxiety disorders.

\section{Implications}

Our study adds to the evidence that HPA axis alterations in depression and anxiety represent a trait factor that may indicate a biological vulnerability for the development of these disorders. Therefore, the cortisol awakening curve may constitute an important endophenotype of depression (and anxiety) for genetic research. Although the clinical relevance of the difference in 1-hour awakening cortisol needs to be explored in further largescale research, there is some evidence that morning cortisol levels predict unfavourable metabolic ${ }^{43}$ and mental health outcomes. ${ }^{44}$

Sophie A. Vreeburg, MD, Department of Psychiatry and the EMGO Institute Sophie A. Vreeburg, MD, Department of Psychiatry and the EMGO Instit
for Health and Care Research, VU University Medical Center Amsterdam; for Health and Care Research, VU University Medical Center Amsterdam;
Catharina A. Hartman, PhD, Department of Psychiatry, University Medical Center Groningen; Witte J. G. Hoogendijk, MD, PhD, Department of Psychiatry and the EMGO Institute for Health and Care Research and Neuroscience Campus Amsterdam, VU University Medical Center Amsterdam; Richard van Dyck, MD, PhD, Department of Psychiatry and the EMGO Institute for Health and Care Research, VU University Medical Center Amsterdam; Frans G. Zitman, MD, PhD, Department of Psychiatry, Leiden University Medical Center; Johan Ormel, PhD, Department of Psychiatry, University Medical Center Groningen; Brenda W. J. H. Penninx, PhD, Department of Psychiatry and the EMGO Institute for Health and Care Research and Neuroscience Campus Amsterdam, VU University Medical Center Amsterdam, Department of Psychiatry, University Medical Center Groningen and Department of Psychiatry, Leiden University Medical Center, The Netherlands

Correspondence: Sophie A. Vreeburg, MD, Department of Psychiatry, VU University Medical Center Amsterdam, A. J. Ernststraat 887, 1081 HL Amsterdam, The Netherlands, Email: s.vreeburg@ggzingeest.nl

First received 21 Dec 2009, final revision 21 Apr 2010, accepted 15 May 2010

\section{References}

1 Carroll BJ, Cassidy F, Naftolowitz D, Tatham, NE, Wilson WH, Iranmanesh A et al. Pathophysiology of hypercortisolism in depression. Acta Psychiatr Scand 2007; 115 (suppl 433): 90-103.
2 Bet PM, Penninx BW, Bochdanovits Z, Uitterlinden AG, Beekman AT, van Schoor NM, et al. Glucocorticoid receptor gene polymorphisms and childhood adversity are associated with depression: new evidence for a gene-environment interaction. Am J Med Genet B Neuropsychiatr Genet 2009; 150B: 660-9.

3 Sullivan PF, Neale MC, Kendler KS. Genetic epidemiology of major depression: review and meta-analysis. Am J Psychiatry 2000; 157: 1552-62.

4 Unschuld PG, Ising $M$, Specht $M$, Erhardt $A$, Ripke $S$, Heck $A$, et al. Polymorphisms in the GAD2 gene-region are associated with susceptibility for unipolar depression and with a risk factor for anxiety disorders. Am J Med Genet B Neuropsychiatr Genet 2009; 150B: 1100-9.

5 Brouwer JP, Appelhof BC, van Rossum EF, Koper JW, Fliers E, Huyser J, et al. Prediction of treatment response by HPA-axis and glucocorticoid receptor polymorphisms in major depression. Psychoneuroendocrinology 2006; 31: 1154-63.

6 Vreeburg SA, Hoogendijk WJ, van Pelt J, Derijk RH, Verhagen JC, van Dyck R, et al. Major depressive disorder and hypothalamic-pituitary-adrenal axis activity: results from a large cohort study. Arch Gen Psychiatry 2009; 66: 617-26.

7 Bhagwagar Z, Cowen PJ. 'It's not over when it's over': persistent neurobiological abnormalities in recovered depressed patients. Psychol Med 2008; 38: 307-13.

8 Vreeburg SA, Zitman FG, van Pelt J, Derijk RH, Verhagen JC, van Dyck R, et al. Salivary cortisol levels in persons with and without different anxiety disorders. Psychosom Med 2010; 72: 340-7.

9 Mannie ZN, Harmer CJ, Cowen PJ. (2007) Increased waking salivary cortisol levels in young people at familial risk of depression. Am J Psychiatry 2007; 164: 617-21.

10 Vinberg M, Bennike B, Kyvik KO, Andersen PK, Kessing LV. Salivary cortisol in unaffected twins discordant for affective disorder. Psychiatry Res, 2008; 161: 292-301.

11 Young EA, Vazquez D, Jiang $H$, Pfeffer CR. Saliva cortisol and response to dexamethasone in children of depressed parents. Biol Psychiatry 2006; 60: $831-6$.

12 Penninx BW, Beekman AT, Smit JH, Zitman FG, Nolen WA, Spinhoven P, et al. The Netherlands Study of Depression and Anxiety (NESDA): rationale, objectives and methods. Int J Methods Psychiatr Res 2008; 17: 121-140.

13 World Health Organization. Composite International Diagnostic Interview (CIDI). Version 2.1. WHO, 1997

14 Beck AT, Epstein N, Brown G, Steer RA. An inventory for measuring clinical anxiety: psychometric properties. J Consult Clin Psychol 1988; 56: 893-7.

15 Rush AJ, Gullion CM, Basco MR, Jarret, RB, Trivedi, MH. The Inventory of Depressive Symptomatology (IDS): psychometric properties. Psychol Med 1996; 26: 477-86.

16 Landman-Peeters KM, Hartman CA, van der Pompe G, den Boer JA, Minderaa RB, Ormel J. Gender differences in the relation between social support, problems in parent-offspring communication, and depression and anxiety. Soc Sci Med, 2005; 60: 2549-59.

17 Kessler RC, Üstün TB. The World Mental Health (WMH) Survey Initiative Version of the World Health Organization (WHO) Composite Diagnostic Interview (CIDI). Int J Methods Psychiatr Res 2004; 13: 93-121.

18 Kirschbaum C, Hellhammer DH. Salivary cortisol in psychobiological research: an overview. Neuropsychobiology 1989; 22: 150-69.

19 Vreeburg, SA, Kruijtzer BP, van Pelt J, van Dyck R, DeRijk RH, Hoogendijk WJ, et al. Associations between sociodemographic, sampling and health factors and various salivary cortisol indicators in a large sample without psychopathology. Psychoneuroendocrinology 2009; 34: 1109-20.

20 Pruessner JC, Kirschbaum C, Meinlschmid G, Hellhammer DH. Two formulas for computation of the area under the curve represent measures of total hormone concentration versus time-dependent change. Psychoneuroendocrinology 2003; 28: 916-31.

21 Edwards S, Clow A, Evans P, Hucklebridge F. Exploration of the awakening cortisol response in relation to diurnal cortisol secretory activity. Life SCi 2001; 68: 2093-103.

22 Fekedulegn DB, Andrew ME, Burchfiel CM, Violanti JM, Hartley TA, Charles LE, et al. Area under the curve and other summary indicators of repeated waking cortisol measurements. Psychosom Med 2007; 69: 651-9.

23 Schmidt-Reinwald A, Pruessner JC, Hellhammer DH, Federenko I, Rohleder N, Schürmeyer $\mathrm{TH}$, et al. The cortisol response to awakening in relation to different challenge tests and a 12-hour cortisol rhythm. Life Sci 1999; 64: 1653-60.

24 Gueorguieva R, Krystal JH. Move over ANOVA: progress in analyzing repeated-measures data and its reflection in papers published in the Archives of General Psychiatry. Arch Gen Psychiatry 2004; 61: 310-7. 
25 Levine DW, Kripke DF, Kaplan RM, Lewis MA, Naughton MJ, Bowen DJ, et al Reliability and validity of the Women's Health Initiative Insomnia Rating Scale. Psychol Assess 2003; 15: 137-48.

26 Craig $C L$, Marshall AL, Sjöström M, Bauman AE, Booth $M L$, Ainsworth $B E$, et al. International physical activity questionnaire: 12-country reliability and validity. Med Sci Sports Exerc 2003; 35: 1381-95.

27 Costa PT, McCrae RR. Domains and facets: hierarchical personality assessment using the revised NEO personality inventory. J Pers Assess 1995 64: 21-50.

28 Brugha $T$, Bebbington $\mathrm{P}$, Tennant $\mathrm{C}$, Hurry J. The List of Threatening Experiences: a subset of 12 life event categories with considerable long-term contextual threat. Psychol Med 1985; 15:189-94.

29 Hellhammer J, Fries E, Schweisthal OW, Schlotz W, Stone AA, Hagemann D. Several daily measurements are necessary to reliably assess the cortisol rise after awakening: state- and trait components. Psychoneuroendocrinology 2007; 32: 80-6.

30 Holsboer F, Lauer CJ, Schreiber W, Krieg JC. Altered hypothalamic-pituitaryadrenocortical regulation in healthy subjects at high familial risk for affective disorders. Neuroendocrinology, 1995; 62: 340-7.

31 Wüst S, Federenko I, Hellhammer DH, Kirschbaum C. Genetic factors, perceived chronic stress, and the free cortisol response to awakening. Psychoneuroendocrinology 2000; 25: 707-20.

32 Kupper N, de Geus EJ, van den Berg M, Kirschbaum C, Boomsma DI, Willemsen G. Familial influences on basal salivary cortisol in an adult population. Psychoneuroendocrinology 2005; 30: 857-68.

33 Wüst S, Kumsta R, Treutlein J, Frank J, Entringer S, Schulze TG, et al. Sex-specific association between the 5-HTT gene-linked polymorphic region and basal cortisol secretion. Psychoneuroendocrinology 2009; 34: 972-82.

34 Murgatroyd C, Patchev AV, Wu Y, Micale V, Bockmühl Y, Fischer D, et al. Dynamic DNA methylation programs persistent adverse effects of early-life stress. Nat Neurosci 2009; 12: 1559-66.

35 Danese A, Pariante CM, Caspi A, Taylor A, Poulton R. Childhood maltreatment predicts adult inflammation in a life-course study. PNAS 2007; 104: 1319-24.
36 Miller GE, Chen E, Kok AK, Walker H, Lim A, Nicholls EF, et al. Low early-life social class leaves a biological residue manifested by decreased glucocorticoid and increased proinflammatory signaling. PNAS 2009; 106: 14716-21.

37 Ellenbogen MA, Hodgins S. Structure provided by parents in middle childhood predicts cortisol reactivity in adolescence among the offspring of parents with bipolar disorder and controls. Psychoneuroendocrinology 2009; 34: 773-85.

38 Ronsaville DS, Municchi G, Laney C, Cizza G, Meyer SE, Haim A, et al. Maternal and environmental factors influence the hypothalamic-pituitaryadrenal axis response to corticotropin-releasing hormone infusion in offspring of mothers with or without mood disorders. Dev Psychopathol 2006; 18: 173-94.

39 Ormel J, Oldehinkel AJ, Nolen WA, Vollebergh W. Psychosocial disability before, during, and after a major depressive episode: a 3-wave populationbased study of state, scar, and trait effects. Arch Gen Psychiatry 2004; 61 387-92.

40 Ormel J, Oldehinkel AJ, Vollebergh W. Vulnerability before, during, and after a major depressive episode: a 3-wave population-based study. Arch Gen Psychiatry 2004; 61: 990-6.

41 Kudielka BM, Broderick JE, Kirschbaum C. Compliance with saliva sampling protocols: electronic monitoring reveals invalid cortisol daytime profiles in noncompliant subjects. Psychosom Med 2003; 65: 313-9.

42 Dockray S, Bhattacharyya MR, Molloy GJ, Steptoe A. The cortisol awakening response in relation to objective and subjective measures of waking in the morning. Psychoneuroendocrinology 2008; 33: 77-82.

43 Dekker MJ, Koper JW, van Aken MO, Pols HA, Hofman A, de Jong FH, et al. Salivary cortisol is related to atherosclerosis of carotid arteries. J Clin Endocrinol Metab 2008; 93: 3741-7.

44 Harris TO, Borsanyi S, Messari S, Stanford K, Cleary SE, Shiers HM, et al Morning cortisol as a risk factor for subsequent major depressive disorder in adult women. Br J Psychiatry 2000; 177: 505-10. 